\title{
Improving Quality of Doctor's Communication Skills
}

\section{S. Tomova (Sarka Tomova), A. Arpova (Anna Arpova)}

St. Elizabeth University of Health and Social Work in Bratislava, SK

\section{Original Article}

\section{E-mail address:}

sarka.tomova@fmotol.cuni.cz

\section{Reprint address:}

Sarka Tomova

Department of Nursing, $2^{\text {nd }}$ Faculty, Charles University

V Uvalu 84

15006 Prague 5

$\mathrm{CZ}$

Source: Clinical Social Work and Health Intervention

Pages: 95 - 100

Volume: 9

Issue: 2

\section{Reviewers:}

Daria Kimuli

Catholic university of Eastern Africa, Nairobi, KE

Harold Baillie

University of Scranton, USA

\section{Key words:}

Communication. Communication skills. Soft skills. Social interaction. Video training.

\section{Publisher:}

International Society of Applied Preventive Medicine i-gap

CSWHI 2018; 9(2): 95 - 100; D0I 10.22359/cswhi_9_2_14 (c) 2018 Clinical Social Work and Health Intervention

\section{Abstract:}

This report is focused on the possibilities of practicing communication and developing communication skills in modern Medical Care. Demand for professionally managed communication between Doctors and patients is part of improving the quality of Medical Care. Future Doctor training in the field of mastering communication skills can be a very significant element at the beginning of their professional career. Effective management of communication skills with the help of appropriate teaching methods has a big influence on acquiring and deepening the 
trust between Doctor and patient. Practicing through role-play and analyzing video-recorded situations is one of the most effective methods of communi-cation training. It is based on students' needs and possibilities arising from effective learning processes.

\section{Introduction}

Social interaction is a fundamental pillar and a starting point of interpersonal contact. Dictionaries define interaction as reciprocal influence of two or more agents. Social inter-action is understood as the basic way of social behavior, experiencing, learning and self-knowledge, communication and mutual influence of at least two people. Therefore it is always about a person and his/her relationships with other people.

Communication is an indispensable part of mutual contact between people. It constitutes an inherent component of mutual connection. It is a complex and multi-level process. It is influenced by many factors, among others for example by a person's individuality; his or her upbringing, education, experiences, abilities etc. Thus, its basis is of a biopsychosocial model of a person. It can certainly differ in development, perception, hereditary dispositions, acquiring communication skills, family upbringing and the way it is realized. Nowadays the notion of communication is overused. A lot of notions are hidden behind the word communication today; they fade and disappear. We are far less likely to find words like talk, chat, discuss, debate, tell, exchange information or experiences etc.; today two people simply communicate. (Linhartová, 2007)

Communication as a connection tool is affected by a range of different individual characteristics. Among others it involves being aware of one's own self, actions and behaviors. With this aim, video training is one of the key activities during practicing communication between Health Care Workers and patients.

\section{Research process, Results and Discussion}

Communication in Health Care is the topic that both laymen and professionals are interested in. Communication level is part of assessing quality of Health Care in a Medical Institution. For this reason several questions in a patient satisfaction questionnaire are usually devoted to how a patient sees the communication among the members of the Health Care team in a certain Institution; being informed about the treatment process; comprehensibility of the information she/ he receives; appropriate choice of language, etc. This increased interest in the last decades is related to the concept of the patient being seen as a partner in Health Care and Medical Care, and therefore to the changed approach to an ill person.

Understanding and communication belong to basic communication notions that come to the foreground in Medical Care. These terms from the sphere of communication and communication skills are referred to as soft skills. Soft skills are related to the way to cooperate, not what to do. WHAT to do belongs to the professional level; HOW to cooperate belongs to the personal human level. This level is affected by a range of factors: for example, how we get along; how we feel; how we think; our hierarchy of values; our motives; rituals; needs; etc. Hard skills, which include language; logical mathematical; visual spatial forms of 
intelligence can be measured by the Intelligence Quotient Test (IQ). In contrast, soft skills are skills in the sphere of interpersonal relations: in the first place how willing and able we are to work on ourselves and whether we look for opportunities to grow personally. (Muhleisen, Oberhuber, 2008)

We can divide soft skills into three notional spheres:

- sphere of personal competencies;

- sphere of social competencies;

- sphere of methodical competencies.

The above mentioned spheres and students showing their effort to develop and grow personally lead us to the idea of working on the topic of communication training for the students of medical faculties. Dictionaries define communicative competence as under-standing verbal and non-verbal interaction; different types of verbal utterances; written and printed texts and records; visual materials; commonly used gestures; facial expressions; pantomime; sounds and other means of information transmission; thinking about them and reacting adequately to them, as well as using them appropriately and adequately for our own accurate and civilized expression; being involved in social coexistence; and events. We consider these skills to be the kind of skills that a Doctor should master in his Medical Practice. Beside the above mentioned communicative competencies, the integral part of Doctor's professional approach are also social and work competencies. They complete the latter and are realized in the first place in the skills to work in a group effectively and in a cultivated way; adequately adapt to one's position and role in a group; positively influence the quality of working together; exert effective working activity and creative effort in the sphere of one's own working activities.
The relationship between Doctor and patient belongs to the basic relationships in Health Care; respectively Medical Care. The profession of a Doctor is the only one that every person is going to deal with inevitably in their life; everybody is going to be a patient eventually. When our health is under threat and our current condition deviates from the norm every one of us starts to realize its meaning and value. Maybe for this reason we expect omnipotent and flawless treatment; an infallible and friendly approach by the Doctor whom we investigate thoroughly in the moments of tension and uncertainty. We expect that the Doctor will hear our fears and concerns; that she or he will be able to choose the right and effective words.

We expect the non-verbal resonance alongside the choice of the most effective methods of therapy. In simple words, we take Doctor's good communication skills for granted. And only misunderstanding of all kinds can make us realize that it is not a matter of course. Nothing is self-understood, it is necessary to master the scientific part connected to the professional communication. (Haškovcová in Ptáček, 2011). Nowadays, Doctors are primarily trained during their university years to be able to treat people; to know and choose the right methods of treatment; view and analyze test results; logically consider connections and links between symptoms. It is done at the expense of suppressing the perception of a person as an individual, and a Doctor is going to learn that only with the beginning of practice.

Teaching communication skills should be based on students' needs in the learning process that are necessary for successful mastering of skills or qualification. According to Petty, explanation belongs to the basic needs of a learning person. Explaining to the student why the mentioned way is 
used is the basis for his or her further understanding. If we apply procedures that we do not understand we often feel uncertain. Within the explanation we should become acquainted with all important context of the topic. As Petty writes, "earning without understanding is superficial." (Petty, 2008, p. 23). As he states further, among other needs of students that arise in the process of learning are demonstration; activity; active revising; testing. During a demonstration the student feels the need to know exactly what is expected from her or him, how to do it in the best possible way; how to use her or his skills correctly; in what situations to use them.

The majority of students rightfully consider training and practical usage of their skills to be the most effective method of learning. Practicing skills takes a disproportionally larger amount of time in the learning process than other activities. From the didactic point of view this aspect is mostly overlooked while teaching communication skills at Medical Faculties. Another need of a student is "testing" which states the efficiency of the acquired skill. Under usual circumstances it is easier to demonstrate ability or skill in the presence of a teacher, mentor etc. than using the skill on one's own.

This last step on the way to mastering a skill or qualification in our case in clinical conditions is the most significant. The student can evaluate this step on his/her own in the practical part of his or her professional training. She or he can assess during communication with patients how well she or he is prepared to manage unpredictable communication barriers and apply acquired communication skills.

For above mentioned reasons we focused on the efficiency of using video records in practicing "active listening" and "information transmission" with the students of General Medicine Master Program (Second Faculty of Medicine at Charles University) during their optional course called "Communication, communication skills'. We chose this optional course since there is no separate subject that deals with communication and basic communi-cation skills in the above mentioned program. During this optional course we had the opportunity to examine and observe progress in developing the two above mentioned communication skills in students of Medicine.

The most appropriate method of assessing the progress seemed to be a video recording of the situation that captured in detail separate subchapters of the situation. During the introduction part of the course, the students had a chance to evaluate and understand the meaning of the observed communication skills - active listening and information transmission based on the example conversation between "Doctor and patient" in the model classroom. Roles of the Doctor and the patient were played by experienced students from senior year of Medical Faculty, who proved their experience in managing the observed communication skills. The conversation was acted out according to the predefined script that was given to both actors and previously approved by the teacher.

- Respondents that took part in the course prepared characteristics of unknown diagnoses based on the example dialogue.

- The choice of a diagnosis was random, so there was enough time provided for working on the topic.

- Students' task was to find and process all information about prevalence, incidence, symptoms, diagnostics, treatment and prognosis of the disease so that they can convey it and explain to the patient or a family member. 
- The element of an unknown diagnosis became very effective in preparing the training, since it encouraged not only individual preparation, but also looking for connections with already acquired knowledge and skills of the students.

It stimulates students' motivation for studying. Patient's role was played by colleagues from senior years or students unknown to the participants who were given the script of their role beforehand. During the course an approximately 10 minute long video recording of a communication situation was made for every individual. This video record was repeated at the end of the course, that is at the end of the semester of the academic year, since the course is one semester long. The differences between video recordings of communication skills at the beginning and at the end of the course for individual students were recorded into special forms that were prepared in advance. Students themselves were the assessors, they observed performances of every student colleague and made notes during or right after the performance. We asked ourselves whether it was possible to divide the communication skills of the students captured by values of individual parameters of all four subchapters into several groups (clusters), which would to some extent differ in character of the communication skills, but so that the students of each group would be close to each other by the values of their communication skills. The point of this division is primarily creating "profile" groups of students according to their communication skills, where the most appropriate representative or representatives of each group will form a so called focal group. For creating groups, we used a multidimensional method - cluster analysis. In this way, every cluster becomes a profile group that can be "accurately" described through average values of communication parameters, for example "talkative extroverts", "responsible introverts" etc. However, it requires great imagination on the side of the researcher as well as understanding the principle of cluster analysis.

\section{Conclusion}

Teaching communication skills at Medical Faculties can be a very distinctive source of detecting weak points in a person's communication that can adversely influence negotiation and behavior in medical practice. Uncertainty in communication with a patient can distract attention from essential information and lack of experience in leading a conversation with ill people may appear stressful not only for the patient but especially for the student during Clinical Practice. Acquiring communication skills with the help of role play and analyzing video recordings can be one of the ways to eliminate uncertainty and fear of direct contact with a patient. The chosen method proves to be effective and exceptional primarily in the sphere of self-concept and self-reflection of students. It helps a student to see her or him own reactions, quality of language means, and in the first place non-verbal cues in the situation where he or she is concentrating on the patient and her or his condition. It is not easy to master all the skills at once, it requires training supplied by feedback that can show progress as well as points that need to be improved. Acquiring communication knowledge and skills and quality training of these skills enables every Doctor to use an individual approach to patients that is constantly emphasized today, and also elevate Doctor's profession to being an art of its kind. 


\section{References}

1. PTACEK R, BARTUNEK P et. al. (2011) Ethics and Communication in Medicine 1. Ed. Praha: Grada. 528 pp. ISBN 978-80247-3976-2.

2. LINHARTOVA V (2007) Practical communication in medicine. 1. Ed. Praha: Grada.. 152 pp. ISBN 978-80-247-1784-5.

3. MUHLEISEN S, OBERHUBER N (2007) Communication and other soft skills. 1. Ed.
Praha: Grada.. 192 pp. ISBN 978-80-2472662-5.

4. PETTY G (2008) Modern teaching. 5. Ed. Praha: Portal.. 380 pp. ISBN 978-80-7367427-4.

5. STATSOFT Inc. (2007) STATISTICA (data analysis software system), verze 8.0. www. statsoft.com.

6. STATSOFT Inc. (2013) Electronic Statistics Textbook. Tulsa, OK: StatSoft. WEB: http:// www.statsoft.com/textbook. 